\title{
Conservation tillage regulates soil bacterial community assemblies, network structures and ecological functions in black soils
}

\section{Zhuxiu Liu}

Northeast Institute of Geography and Agroecology, Chinese Academy of Sciences

Haidong Gu

Northeast Institute of Geography and Agroecology, Chinese Academy of Sciences

\section{Aizhen Liang}

Northeast Institute of Geography and Agroecology, Chinese Academy of Sciences

\section{Lujun Li}

Northeast Institute of Geography and Agroecology, Chinese Academy of Sciences

\section{Qin Yao}

Heilongjiang Bayi Agricultural University

\section{Yanxia Xu}

Branch of Animal Husbandry and Veterinary of Heilongjiang Academy of Agricultural Sciences

Junjie Liu ( $\square$ liujunjie@iga.ac.cn )

Northeast Institute of Geography and Agroecology Chinese Academy of Sciences

Jian Jin

Northeast Institute of Geography and Agroecology, Chinese Academy of SciencesNortheast Institute of Geography and Agroecology, Chinese Academy of Sciences

Xiaobing Liu

Northeast Institute of Geography and Agroecology, Chinese Academy of Sciences

\section{Guanghua Wang}

Northeast Institute of Geography and Agroecology, Chinese Academy of Sciences

\section{Research Article}

Keywords: three tillage practices, nitrogen cycle, carbon degradation, bacterial networks, assembly processes

Posted Date: June 21st, 2021

DOI: https://doi.org/10.21203/rs.3.rs-580080/v1 
License: (c) (i) This work is licensed under a Creative Commons Attribution 4.0 International License. Read Full License

Version of Record: A version of this preprint was published at Plant and Soil on January 19th, 2022. See the published version at https://doi.org/10.1007/s11104-021-05219-x. 


\section{Abstract \\ Aims}

Conventional tillage is a serious threat to the stability of soil ecosystems. Understanding the response mechanisms of soil microbial community assemblies to anthropogenic activities is a major topic of ecological research.

\section{Methods}

Here, we investigated the bacterial community structures and assemblies in bulk and rhizosphere soils of soybeans grown with conventional tillage (moldboard plow, MP) and with conservation tillage that involved no-tillage (NT) or ridge tillage (RT) using high-throughput sequencing methods.

\section{Results}

We found that soil bacterial community compositions, structures and assembly processes were primarily altered by tillage practices. Briefly, in comparison to MP, NT and RT increased the relative abundances of the nitrogen-fixing bacteria Mesorhizobium sp., Bradyrhizobium sp. and Burkholderia sp., but decreased the abundance of soil carbon-degrading bacteria, especially Blastococcus sp., Streptomyces sp. and Sphingomonas sp. In addition, in comparison to MP, NT and RT resulted in more stable bacterial networks and more lower the relative contribution of homogenizing dispersal. Soil pH was the primary soil factor regulating both the bacterial community structures and assembly processes under the three tillage practices.

\section{Conclusions}

The altered functional bacteria under conservation tillage was mostly affiliated with biomarkers and keystone taxa, inferring that conservation tillage might contribute to biological nitrogen fixation and soil carbon sequestration.

\section{Introduction}

Black soils (Mollisols) are highly productive and play key roles in ensuring food security in China (Liu et al., 2008). Tillage practices aim to improve crop production and agricultural sustainability through soil mechanical inversion and residue return (Dang et al, 2015; Zuber and Villamil, 2016). However, the intensive mechanical interference of conventional tillage, such as moldboard plows (MPs), leads to serious soil degradation, which is a major threat to the health of agricultural ecosystems (Montgomery, 2007; Sainju et al., 2011; Zhang et al., 2012). In contrast, conservation tillage, such as the practice of notillage (NT), which minimizes soil erosion risks and input costs, is adopted to combat agricultural scourge 
(Busari et al., 2015; Zhao et al., 2017). Despite the benefits of NT, the key disadvantages are that it causes herbicide-resistant weeds to thrive and the soil surface to become compacted, which impede normal root development, reduces the seed germination rate, and increases stubble-borne diseases (Dang et al., 2015; Steinkellner and Langer, 2004; Sun et al., 2018a). Therefore, compared with NT and MP, the conservation tillage practice of ridge tillage (RT) with low soil disturbance increases soil resilience and maximizes the positive impacts on soil quality (Alvear et al., 2005; Hobbs et al., 2008).

Tillage practices change soil properties and thus lead to variations in soil microorganisms, which play a considerable role in agroecosystems by mediating soil biogeochemical processes and plant nutrient uptake (Falkowski et al., 2008; Fierer, 2017). However, most studies on the influences of tillage practices on soil microorganisms have focused on microbial community composition and diversity, but a few have focused on microbial ecological functions. The results of long-term local experiments have revealed that conservational tillage enhances soil biological nitrogen fixation by increasing the abundances of Pseudomonas spp. and Agrobacterium spp. (Hoflich et al., 1999; Wang et al., 2020a), but other studies have found that conservation tillage increases denitrifiers, which in turn promotes soil nitrogen loss (Johnson and Hoyt, 1999; Puerta et al., 2019). In addition, it is still not well understood how tillage practices impact soil carbon cycling with shifts in microbial communities between conventional and conservation tillage. Evidence has revealed that NT increases the abundance of anaerobes with low carbon utilization efficiency and reduces the abundance of cellulose-degrading groups, thus encouraging soil carbon sequestration (Allison et al., 2010; Sun et al., 2018b; Wang et al., 2020b). However, de Vries et al. (2015) documented that there is no obvious variation in cellulose-degrading communities among different tillage practices based on metagenomic analyses. Therefore, it is important to comprehensively understand the ecological functions of soil microorganisms under different tillage practices to improve the productivity and sustainable development of agricultural ecosystems. However, studies of soil microbial functions are not easy because of the complex interactions between microbes. Recently, microbial networks and community assembly processes were used to determine these complex relationships while providing insight into the response of soil microbiomes to anthropogenic and environmental changes (Banerjee et al., 2019; Ye et al., 2021; Zhou and Ning, 2017).

It is widely accepted that stochastic (neutral theory) and deterministic (niche-based theory) processes both simultaneously influence microbial community assemblies (Feng et al., 2018; Stegen et al., 2012). Nevertheless, the importance of stochastic and deterministic processes to microbial community assembly is still debated. A conceptual framework dividing ecological processes into five fundamental processes, including homogenizing dispersal, dispersal limitation, homogeneous selection and variable selection, as well as "undominated processes", which indicate those not dominated by any of the above single processes, has been developed and widely used to quantify the relative contributions of these processes (Stegen et al., 2015). Empirical evidence supports that community assemblies are driven by different combinations of these ecological processes. Recent studies have shown that deterministic processes determine the assembly of soil bacterial communities in wheat fields (Shi et al., 2018). Jiao and Lu (2020) found that homogeneous selection dominates the soil bacterial community assembly processes in rice and maize fields. Cheng et al. (2021) confirmed that variable selection has the greatest 
contribution to soil bacterial community assembly processes in arable and forest soils. However, an understanding of the relative effects of these ecological processes on the assembly of soil bacterial communities under different soil tillage practices and their consequences for ecosystem functionality is lacking.

In this study, bulk and rhizosphere soils from soybean plants were collected to explore the compositions, network structures and assembly processes of bacterial communities under conventional tillage (MP) and conservation tillage (NT and RT) practices in Northeast China using high-throughput sequencing methods. We aimed to 1) reveal the bacterial community structures and the variations in the functional taxa in response to the three tillage practices; 2) illuminate how the network properties and keystone taxa varied among NT, RT and MP; and 3) clarify the relative contribution of ecological processes in shaping the assembly of bacterial communities under these three tillage practices.

\section{Materials And Methods}

Experimental design and soil sampling collection

A long-term experimental station was established at the Northeast Institute of Geography and Agroecology, Chinese Academy of Sciences, Changchun, Jilin, China $\left(44^{\circ} 59^{\prime} \mathrm{N}, 125^{\circ} 23^{\prime} \mathrm{E}\right)$ in the fall of 2013. The average yearly precipitation at the experimental site is $614 \mathrm{~mm}$, and the mean annual temperature is $6.4^{\circ} \mathrm{C}$. The soil samples belong to black soil that is classified as Mollisols according to the soil taxonomy system of the US.

The experiment was arranged with a completely randomized block design. Three tillage treatments were selected for this study: moldboard plow (MP) tillage, no-tillage (NT) and ridge tillage (RT). Except for sowing with a KINZE-3000NT planter (lowa, USA), the soil under NT was not disturbed. For RT, only ridging with a cultivator was conducted in June of each year. The MP site was disturbed by moldboard plowing $(0-20 \mathrm{~cm})$ after the harvest of the maize, during seedbed preparation in spring, and during the ridge process in June. For all treatments, a soybean and maize rotation was implemented and maize straw of approximately $30 \mathrm{~cm}$ in length or all soybean residues covered the soil surface after the annual harvest. For soybean, potassium $(K)$, phosphorus $(P)$ and nitrogen $(N)$ fertilizers were applied at $80 \mathrm{~kg}$ $\mathrm{ha}^{-1}, 60 \mathrm{~kg} \mathrm{ha}^{-1}$, and $40 \mathrm{~kg} \mathrm{ha}^{-1}$, respectively, as basal fertilizers. For maize, basal fertilizer was applied

at $78 \mathrm{~kg} \mathrm{~K} \mathrm{ha}^{-1}, 45.5 \mathrm{~kg} \mathrm{P} \mathrm{ha}^{-1}$ and $100 \mathrm{~kg} \mathrm{~N} \mathrm{ha}^{-1}$, whereas an additional $50 \mathrm{~kg} \mathrm{~N} \mathrm{ha}^{-1}$ was used at the V6 stage as the top dressing.

A total of 48 soil samples (bulk and rhizosphere, three treatments $\times$ eight replicates) were collected on July 25,2017 , at the soybean podding stage. Soil $(0-20 \mathrm{~cm})$ was randomly collected from each soybean plot $(25 \mathrm{~m} \times 7.8 \mathrm{~m})$ as bulk soil. To collect the rhizosphere soil samples, ten soybean plants in each plot were shoveled out. After shaking off the loose adhesive soil on the root, the tightly bonded soil on the root surface was brushed down as rhizosphere soil (Philippot et al., 2013). The collected soils were kept in $-80^{\circ} \mathrm{C}$ and $4^{\circ} \mathrm{C}$ refrigerators for soil DNA extraction and chemical property analysis, respectively. 
Soil chemical properties analysis

Soil chemical properties were assayed according to the description by Lu (1999) after being passed through a $2 \mathrm{~mm}$ sieve. The specific data on soil $\mathrm{pH}$, nitrate nitrogen $\left(\mathrm{NO}_{3}{ }^{-} \mathrm{N}\right)$, ammonium nitrogen $\left(\mathrm{NH}_{4}{ }^{+}\right.$ $N$ ), available phosphorus (AP), available potassium (AK), total nitrogen (TN), total carbon (TC), total potassium (TK) and total phosphorus (TP) are shown in Table S1. Briefly, in comparison to the bulk soil, the rhizosphere soil had higher TC, $\mathrm{TN}$ and available nutrients $\left(\mathrm{NO}_{3}{ }^{-}-\mathrm{N}, \mathrm{NH}_{4}{ }^{+}-\mathrm{N}, \mathrm{AK}\right.$ and $\left.\mathrm{AP}\right)$. In addition, in comparison to NT and RT, MP significantly increased $\mathrm{NO}_{3}{ }^{-}-\mathrm{N}$ and pH in the bulk and rhizosphere soils and $A P, T P$ and $T C$ in the rhizosphere soil.

Soil DNA extraction and sequencing

Soil microbial total DNA was extracted ( $0.5 \mathrm{~g}$ fresh soil per sample) using the Fast DNA® Spin Kit for Soil (MP Biomedicals, USA). The primer pair 338F/806R (Castrillo et al., 2017), with a sample-specific barcode at the 5 ' end, was used to amplify the V3-V4 region of the soil bacterial 16S rRNA gene. The PCR system and amplification conditions were described previously (Liu et al., 2020). The PCR products were further pooled and purified by an agarose gel DNA purification kit (TaKaRa, Dalian, China). The purified PCR products were sequenced on an Illumina MiSeq platform at Majorbio Bio-Pharm Technology Co., Ltd. (Shanghai, China).

Bioinformatic analysis

The QIIME pipeline (version 1.9.1) was used to perform raw FASTAQ data analysis (Caporaso et al., 2010). First, low-quality sequences with an average quality score $<20$ and/or length $<200$ bp were removed (Aronesty, 2011). The UCHIME algorithm was used to filter chimera sequences (Edgar et al., 2011). Then, the obtained high-quality sequences were clustered into operational taxonomic units (OTUs) with a $97 \%$ similarity level by UPARSE (Edgar, 2010). The OTU representative sequences were identified taxonomically using the RDP classifier based on the SILVA database for bacterial species classification (Cole et al., 2005). Our raw sequences were submitted to the NCBI Sequence Read Archive (SRA) database with the accession number PRJNA644753.

Community assembly process analysis

A null model was employed to evaluate the bacterial community assembly processes. Phylogenetic conservatism of communities was tested using the function 'mantel.correlog' in the "vegan" package of R (version 3.6.2) (R Development Core Team, 2016) before building the null model (Stegen et al., 2013). To identify the bacterial community assembly processes within each sample, the standardized effect size measure of the mean nearest taxon distance (ses.MNTD) was calculated using the "picante" package in the R environment ('taxa.labels' function, 999 randomization). The positive and negative values of ses.MNTD indicated phylogenetic overdispersion and phylogenetic clustering, respectively (Webb et al., 2002). 
We quantified the influences of stochastic and deterministic processes on bacterial assemblage by the nearest taxon index ( $\beta N T I)$ ('comdistnt' function, abundance. weighted = TRUE), which is the standard deviation of the between-community mean nearest taxon distance (BMNTD) (Stegen et al., 2012). Values of $|\beta N T| \mid>2$ indicate a significant deviation between observed and expected phylogenetic turnover, which indicates the dominance of deterministic processes. $\beta N T I$ values $<-2$ and $>+2$ denote homogeneous selection (lower phylogenetic turnover than expected) and variable selection (higher phylogenetic turnover than expected) processes, respectively (Stegen et al., 2012). Furthermore, we combined BNTI with the Bray-Curtis-based Raup-Crick ( $\left.\mathrm{RC}_{\text {bray }}\right)$ to quantify the effects of dispersal-based stochastic ecological processes (Stegen et al., 2013, 2015). $\mathrm{RC}_{\text {bray }}$ values $<-0.95$ or $>+0.95$ denote distinct divergence from the null model expectation. The homogenizing dispersal and dispersal limitation processes were quantified by $|\beta N T| \mid$ values $<2$ but $\mathrm{RC}_{\text {bray }}<-0.95$ and $\mathrm{RC}_{\text {bray }}>+0.95$, respectively. Moreover, $|\beta N T| \mid<2$ and $\left|\mathrm{RC}_{\text {bray }}\right|<0.95$ were considered undominated processes (Stegen et al., 2015). The "picante" package in the R environment was used to perform the above analyses (R Development Core Team, 2016).

\section{Co-occurrence network construction}

To determine the bacterial species interactions, co-occurrence networks were constructed with OTUs with relative abundances $>0.01 \%$ to rule out spurious correlations. The topological indices of random empirical networks were summarized by 999 iterations to determine whether network properties were error prone. Ten nodes with the highest degree were defined as hub nodes (Ma et al., 2020). The role of individual nodes was divided into four categories: network hubs, connectors, module hubs and peripherals (Olesen et al., 2007). Ecologically, peripheral nodes represent specialists, while the other three represent generalists (Deng et al., 2012). The generalists and hub nodes together were considered keystone taxa in this study. Gephi (version 0.9.2) was applied to visualize the co-occurrence network.

Statistical analyses

In this study, we randomly selected 21,900 bacterial sequences from each sample to compare the relative variation between samples. One-way ANOVA was conducted to test the divergences in the measured variables among the treatments. The changes in the bacterial community composition and abundance at the phylum, genus and OTU levels among the tillage practices were determined with heatmaps, circles and ternary plots, which were displayed in the R environment with the "pheatmap", "circlize" and "ggtern" packages, respectively (R Development Core Team, 2016). In addition, the non-parametric multivariate analysis of variance (Adonis) and principal coordinate analysis (PCOA) were carried out using the "vegan" package in the $\mathrm{R}$ environment to reveal the influence of different disturbance degrees on bacterial community structures. The correlation between bacterial communities and soil chemical properties was performed by the Mantel test and distance-based redundancy analysis (db-RDA) using the "vegan" package in the $\mathrm{R}$ environment. The ecological function of the bacterial communities was predicted using FAPROTAX (Louca et al., 2016). To identify the biomarkers, random forest modeling was performed using the "randomForest" package in the $\mathrm{R}$ environment. 


\section{Results}

Bacterial community composition

In this study, 1,740,398 high-quality bacterial sequences were obtained from 48 soil samples $(30,182$ 44,915 per sample), which were clustered into 4,649 OTUs belonging to 38 phyla. The dominant bacterial phyla/classes (with average relative abundances higher than $5 \%$ ) were Alphaproteobacteria (23.25\%), Actinobacteria (20.07\%), Acidobacteria (11.45\%), Betaproteobacteria (9.95\%), Chloroflexi (8.09\%) and Bacteroidetes (6.13\%) across all samples (Fig. 1, Table S2). In the bulk soil, in comparison to MP, NT and RT significantly increased $(P<0.05)$ the relative abundance of Nitrospirae while reducing the abundance of Saccharibacteria. Additionally, the relative abundances of Gemmatimonadetes and Actinobacteria were significantly lower $(P<0.05)$ in NT and RT than in MP in the rhizosphere soils (Table S2).

Fifty-two genera were observed with mean relative abundances higher than $0.5 \%$ in at least one treatment. Among them, Bradyrhizobium (6.81\%) and Sphingomonas (3.22\%) were the most dominant genera. In the bulk soils, in comparison to MP, NT and RT significantly increased $(P<0.05)$ the relative abundances of three genera, including Bacillus, Mesorhizobium and RB41, while they decreased the abundances of 12 genera, including Blastococcus, Sphingomonas and Methylobacterium. In the rhizosphere soils, Burkholderia, Mesorhizobium and Aquicella significantly increased $(P<0.05)$, while nine genera, including Mycobacterium, Methylotenera and Gemmatimonas, decreased in NT and RT compared with in MP (Table S2).

At the OTU level, the numbers of unique and shared OTUs among the three tillage practices in the bulk and rhizosphere soils were displayed by a Venn diagram (Fig. 2a and b). In general, in comparison to the bulk soils $(5.95 \%)$, the rhizosphere soils $(10.78 \%)$ had more unique OTUs, irrespective of the tillage practice. Additionally, the differences in the relative abundance of soil bacterial OTUs among the three tillage practices were further revealed by ternary plots (Fig. $2 \mathrm{c}$ and d). The results showed that there were more OTUs altered with specific tillage practices in the bulk soils (158 OTUs) than in the rhizosphere soils (72 OTUs). Specifically, in comparison to MP, NT and RT significantly increased $(P<0.05)$ the relative abundances of OTU2114 (Mesorhizobium) and OTU1206 (Dehalogenimonas) while decreasing the abundances of seven OTUs, including OTU1829 (Blastococcus), OTU846 (Sphingomonas) and OTU3866 (Gemmatirosa), in the bulk soils. Six OTUs, including OTU4404 (Bradyrhizobium), OTU2109 (Rhizobium) and OTU3445 (Burkholderia), remarkably increased $(P<0.05)$, and six OTUs, including OTU1829 (Blastococcus), 0TU846 (Sphingomonas) and OTU3141 (Methylotenera), decreased in the rhizosphere soils with NT and RT compared with those with MP (Fig. 2c and d, Table S3).

Soil bacterial community structure

The PCoA plot based on the Bray-Curtis distance clearly showed that the bacterial communities were mainly divided into two major groups with the bulk and rhizosphere soil samples (Adonis tests, $P<0.001$ ) (Fig. 3a). In addition, the separated PCoA plots based on the bulk and rhizosphere soils individually 
showed that the three tillage treatments significantly altered the bacterial communities (Adonis tests, $P<$ 0.01) (Fig. 3b and c, Table S4).

The results of the Mantel test revealed that soil pH, C/N, TC, TN, TP, AP, AK, $\mathrm{NH}_{4}{ }^{+}-\mathrm{N}$ and $\mathrm{NO}_{3}{ }^{-}-\mathrm{N}$ were significantly correlated with the bacterial community structures $(P<0.05)$ (Fig. S1). After variance inflation factor (VIF) screening, db-RDA showed that $\mathrm{NH}_{4}{ }^{+}$-N played the most important role $\left(\mathrm{R}^{2}=0.740, P\right.$ $<0.001)$ in regulating the bacterial community structures under three tillage practices in combination with the bulk and rhizosphere soils (Fig. 3d, Table S5). Furthermore, the separated db-RDA plots revealed that of the factors, $\mathrm{pH}$ contributed the most to the variations in the bacterial community structures under different tillage practices in both the bulk $\left(R^{2}=0.728, P<0.001\right)$ and rhizosphere $\left(R^{2}=0.698, P<0.001\right)$ soils (Fig. 3e and f, Table S5).

Functional annotation and biomarker identification

In this study, we observed that the dominant functional groups (mean relative abundances higher than $1 \%$ ) were associated with the carbon cycles, including aerobic chemoheterotrophy, chemoheterotrophy and aromatic compound degradation, based on FAPROTAX annotation. The relative abundance of the aforementioned groups was significantly decreased in RT compared with that in MP in bulk soils. In comparison to MP, NT and RT distinctly reduced the relative abundance of aromatic compound degradation in the rhizosphere soils (Fig. 4). In addition, the dominant functional groups were involved in the nitrogen cycles that involved nitrogen fixation, ureolysis, nitrification, nitrate reduction and aerobic ammonia oxidation. Compared with MP, NT and RT significantly increased the relative abundances of nitrification, aerobic ammonia oxidation and nitrate reduction in the bulk soils. Compared to MP, NT and RT increased the relative abundance of nitrogen fixation, and NT increased nitrification and aerobic ammonia oxidation in the rhizosphere soils (Fig. 4).

Random forest analysis based on machine learning was carried out to identify biomarkers (Fig. 5a). A tenfold cross-validation was performed to assess the importance of biomarkers since the error rate of cross-validation tended to stabilize when the 10 most relevant genera were selected. Ten genera were defined as biomarkers: Methylotenera, Gemmatimonas, Burkholderia, Segetibacter, Gemmatirosa, Luteibacter, Noviherbaspirillum, Methylobacterium, Blastococcus and Mycobacterium. The relative abundance of the biomarkers in the different treatments was further illustrated by a heatmap, which showed that most of the biomarkers, such as Methylotenera, Blastococcus and Gemmatimonas, had lower relative abundance values, while only Burkholderia had a relatively higher abundance in the rhizosphere soils of NT and RT than those of MP (Fig. 5b).

Network analysis

To determine the interactions of soil bacterial communities and their potential roles in response to tillage practices, six bacterial co-occurrence networks were constructed for three tillage practices in the bulk and rhizosphere soils (Fig. 6, Table S6). The bacterial co-occurrence networks displayed differences in 
network structures and topological properties among the different tillage practices. The number of edges was higher values with NT than with RT and MP in the bulk and rhizosphere soils. The number of nodes increased with NT and RT in the bulk and rhizosphere soils, respectively, in comparison to that with MP. Additionally, the average clustering coefficient (avgCC) and average connectivity (avgK) of the network were greater with NT than with RT and MP, whereas in comparison to NT and MP, RT resulted in greater modularity (M) and average path distance (GD).

We observed that the degree of hub nodes and the number of generalists were higher with NT than with RT and MP in both the bulk and rhizosphere soils. In the bulk soils, most of the hub nodes were affiliated with Acidobacteria under the three tillage practices. The majority of the hub nodes that occurred with MP belonged to Acidobacteria, while the hub nodes of Actinobacteria and Proteobacteria (Alpha-, Beta- and Gamma-) were dominant when NT and RT were used in the rhizosphere soils (Table S7). Intriguingly, some functional OTUs, such as OTU2160 (Brevundimonas) and OTU3445 (Burkholderia) in NT and OTU2736 (Rhizobacter) and OTU2500 (Nitrosospira), were shared by hub nodes and generalists with the use of RT in the rhizosphere soils. The other OTUs which were shared by hub nodes and generalists belonged to Acidobacteria, including OTU2346 (Stenotrophobacter) with in the rhizosphere soils with MP and OTU2900 (Vicinamibacter), OTU567 (Stenotrophobacter) and OTU3322 (Unclassified) in the bulk soils with the three tillage practices (Tables S7 and S8).

Soil bacterial community assembly processes

The values of ses.MNTD were significantly less than zero across all samples and was lower in the bulk soils than in the rhizosphere soils $(P<0.05)(\mathrm{Fig} .7 \mathrm{a})$, suggesting that the bacterial communities were more phylogenetically clustered in the bulk soils. Additionally, a significant phylogenetic signal was observed across short phylogenetic distances by the phylogenetic mantel correlogram (Fig. 7b). The combined results of $\beta \mathrm{NTI}$ and $\mathrm{RC}_{\text {bray }}$ showed that no homogeneous selection was observed in the deterministic processes, while only homogenizing dispersal and undominated processes were detected for the stochastic processes (Fig. 7c). Variable selection dominated the bacterial community assembly processes across all the tillage practices, while it played a greater role in the bulk soils than in the rhizosphere soils. Homogenizing dispersal contributed more to the bacterial community assembly processes in the bulk and rhizosphere soils with MP than in those with NT and RT. In comparison to RT, NT increased the importance of stochastic processes in the bulk and rhizosphere soils. Additionally, the Mantel test showed that soil pH was significantly correlated $(P<0.05)$ with $\beta \mathrm{NTI}$ (Fig. S1).

\section{Discussion}

Bacterial community structures significantly affected by tillage practices

In this study, irrespective of the tillage practice, soil bacterial communities were divided into two major groups according to the bulk and rhizosphere soil samples, suggesting that rhizosphere effort rather than tillage practice was the dominant factor in regulating the bacterial communities (Fig. 3a). However, the 
bacterial communities were also significantly affected by the tillage practices in the bulk and rhizosphere soils (Fig. 3b and c). This finding is corroborated by Tyler (2019) and Xia et al. (2019), who observed that underlying soil properties varied under different tillage practices and were the dominant factors in shifting microbial communities. Intriguingly, we observed that the variations in the bacterial community structures in the bulk soils were larger than those in the rhizosphere soils, which were likely because the stronger determinant of root exudates released from the roots onto the bacterial communities concealed the variation between tillage practices (Philippot et al., 2013).

Soil chemical properties had significant effects on bacterial community structure in the bulk and rhizosphere soils (Fig. S1). Soil $\mathrm{NH}_{4}{ }^{+}-\mathrm{N}$ played a dominant role in driving differentiation across all soil samples (Fig. 3d). Soil available nitrogen observably affects plant growth, and its uptake by plants is strongly dependent on rhizosphere microbial guilds (Moreau et al., 2019). In this study, the $\mathrm{NH}_{4}{ }^{+}-\mathrm{N}$ content ranged from an average of $1.75 \mathrm{mg} \mathrm{kg}^{-1}$ in the bulk soils to $4.36 \mathrm{mg} \mathrm{kg}^{-1}$ in the rhizosphere soils (Table S1); thus, it is reasonable that a large variation in soil $\mathrm{NH}_{4}{ }^{+}-\mathrm{N}$ contributed the most to shaping the bacterial community structures of all the samples across the bulk and rhizosphere soils. Additionally, soil $\mathrm{pH}$ had contributed the most to regulating the bacterial community structures in the bulk and rhizosphere soils (Fig. $3 e$ and f), although soil pH varied by only 0.3 units among the three tillage practices. This finding suggested that even a small $\mathrm{pH}$ range change induced by tillage practices was still the most important factor determining soil bacterial community compositions (Degrune et al., 2015). This result occurred because of the narrow optimum soil $\mathrm{pH}$ range for bacteria, and when $\mathrm{pH}$ values exceed a certain range, they can directly cause a physiological constraint on soil bacteria that will change the competition outcomes or decrease the net growth of the individual groups that cannot survive (Lauber et al., 2009).

Variations in soil bacterial community compositions induced by different tillage practices

We discovered that the tillage practices displayed species-specific effects on the bacterial communities in both the bulk and rhizosphere soils. Although the degree of differentiation in the soil bacterial community structures among the tillage practices in the bulk soils was larger than that in the rhizosphere soils, more unique species induced by tillage practices occurred in the rhizosphere soils than in the bulk soils (Fig. 2a and $b$ ). This result is understandable because the rhizosphere has a more resource-enriched environment owing to the variety of carbon and nutrients provided by root exudates, which reduces microbial competition and thus allows more species to maintain their lives freely (Costello et al., 2012). However, fewer changes in OTU numbers were observed in the rhizosphere soils than in the bulk soils (Fig. $2 \mathrm{c}$ and d). The results are consistent with those of Thebault and Fontaine (2010), who showed that in comparison to bulk soils, rhizosphere soils have greater ecological stability. This may be explained by plant roots only selectively enriching microbes with specific functions (Berendsen et al., 2012; Yan et al., 2017), which leads to a strong carbon mineralization capacity and rapid nutrient cycling in rhizosphere soils (Fan et al., 2017; Turner et al., 2013).

The responses of the functional bacteria involved in carbon and nitrogen cycling to different soil disturbances were diverse (Tables S2 and S3). NT and RT in the bulk and rhizosphere soils significantly 
reduced the relative abundances of OTU1829 and OTU846, which were affiliated with Blastococcus that can degrade soil organic matter (Wang et al., 2020c) and Sphingomonas that can degrade polycyclic aromatic hydrocarbons (Macchi et al., 2018). OTU3343 (Streptomyces adustus) and OTU3407 (Streptomyces yanglinensis) can effectively degrade lignocellulose (Noda et al., 2012) and had lower abundances in the bulk soils with RT and in the rhizosphere soils with NT. These results indicate that intensive disturbance may accelerate the decomposition of carbon sources (Wang et al., 2020c) because the increased disturbance would increase the soil surface area by forming more microaggregates (Six et al., 2000).

In contrast, Nitrospirae, which contains many nitrifiers, was enriched in the bulk soils with NT and RT and likely enhanced the nitrogen turnover capacity of conservation tillage (Xue et al., 2020). In brief, the representative sequences of OTU3445 and OTU2114 had $97.12 \%$ and $99.53 \%$ similarity to Burkholderia singularis and Mesorhizobium gobiense, respectively. Burkholderia and Mesorhizobium have been widely reported to have nitrogen fixation capabilities (Fan et al., 2019; Soe et al., 2020), and their abundances were significantly higher in the rhizosphere soils with NT and RT than in those with MP. OTU2806 (Nitrosospira multiformis) and OTU3942 (Nitrosospira tenuis), which play a pivotal role in the nitrification process (Lin et al., 2018), were enriched in the bulk soils with RT and rhizosphere soils with NT. OTU4404 (Bradyrhizobium japonicum) and OTU2109 (Rhizobium et/i) are widely documented to facilitate nodulation and biological nitrogen fixation of legumes (Kalita and Malek, 2020; Rivas et al., 2009; Roper et al., 2020), and they increased in the rhizosphere soils with NT and RT. Therefore, given the changes in the relative abundances of the bacterial taxa associated with carbon and nitrogen cycling in the soils with NT and RT compared with that with MP, we speculate that conservation tillage might enhance the soil nitrogen cycle and weaken soil carbon degradation. This concept was reconfirmed by the FAPROTAX annotation; NT and RT reduced the relative abundance of the functional groups associated with aromatic compound degradation while increasing nitrogen fixation in the rhizosphere soils (Fig. 4).

Tillage practices affect the stability of the soil bacterial network and the ecological function of keystone taxa and candidate biomarkers

Network analysis offers deep insight into the complex interactions of bacterial communities under soil perturbations (Barberan et al., 2012). Our study observed that tillage practices had impacts on bacterial network structures (Fig. 6, Table S6). The network of NT with the largest edge displayed more complex interactions among the OTUs in the bulk and rhizosphere soils, even though the NT network possessed relatively fewer nodes than the MP and RT network in the rhizosphere soils. This finding was in line with the results of Banerjee et al. (2019), who observed that the complexity of microbial networks is determined by the number of associations rather than the number of taxa. Additionally, the highest avgK of the NT network in the bulk and rhizosphere soils also demonstrated that in comparison to MP, NT created a higher density of interactions among OTUs (Ma et al., 2020). Bouizgarne et al. (2014) showed that closely coupled OTUs share the same habitat preferences, and their simultaneous occurrence markedly alleviates environmental stresses and stimulates crop growth. Additionally, a network with a greater average path distance (GD) can enable environmental fluctuations to propagate more slowly to 
the whole network, thus playing a better role in buffering environmental perturbations (Wang et al., 2014). Simultaneously, higher modularity (M) was conducive to enhancing the stability of network structures (Kitano, 2004; Krause et al., 2003). Therefore, the higher values of GD and M in the bulk and rhizosphere soils of the RT network indicated that in comparison to MP, RT was more robust to environmental disturbances.

As gatekeepers of ecosystem function, keystone species provide important contributions to biogeochemical cycling (Banerjee et al., 2018; Jiang et al., 2017). It has been widely reported that generalists with important topological roles and hub nodes with the highest degree exert a considerable influence on microbial network structure and function (Banerjee et al., 2019; Herren and McMahon, 2018; Shi et al., 2020). In this study, it was common for the Acidobacteria OTUs to be identified as keystone taxa because Acidobacteria can occupy a broad niche and have traits related to degrading soil organic carbon (Jiang et al., 2017; Mannisto et al., 2013). Additionally, half of the biomarkers were also tied to the soil carbon cycle, including Methylotenera, Gemmatimonas, Methylobacterium, Blastococcus and Mycobacterium (Guo et al., 2016; Kalyuzhnaya et al., 2012; Ren et al., 2017; Sanjenbam et al., 2020; Wang et al., 2020c). More notably, some keystone taxa were simultaneously identified by generalists and hub nodes, which might be explained by their particularly important ecological functions. For instance, the keystone taxa OTU2160 (Brevundimonas) and OTU3445 (Burkholderia) in rhizosphere soils with NT have been reported to be diazotrophic and can enhance crop growth and root colonization (Fan et al., 2019; Naqqash et al., 2020). The OTU2500 and OTU2736 in the rhizosphere soils with RT were classified as Nitrosospira and Rhizobacter, respectively, and these bacteria are well known to play a crucial role in nitrification and nitrogen fixation (Lin et al., 2018; Tong et al., 2020). We also found that the nitrogenfixing bacterium Burkholderia was identified as a biomarker based on random forest analysis (Fig. 5). Overall, the soil bacteria closely involved in soil carbon and nitrogen cycling were integrated as keystone taxa and biomarkers, indicating that tillage practices changed microbial-mediated carbon and nitrogen cycling, thereby affecting ecological functions.

Assembly of soil bacterial communities influenced by tillage practices

In this study, we revealed that stochastic and deterministic processes played a role in the assembly of bacterial communities by null models (Ofiteru et al., 2010). Soil bacterial communities were more closely phylogenetically clustered in the bulk soils than in the rhizosphere soils (Fig. 7a). The weak phylogenetic clustering in the rhizosphere soils might be tied to the reduced relative contribution of deterministic processes, owing to less variable environmental filtering in the rhizosphere soils, which can cause phylogenetic overdispersion of bacterial communities (Fan et al., 2017; Goberna et al., 2014). Additionally, the increasing relative importance of stochastic processes in rhizosphere soils was well associated with higher soil fertility, which can weaken niche selection by promoting the growth of soil microorganisms and reducing competition for resources (Chen et al., 2017; Zhou et al., 2014). We found that stochastic processes, especially homogenizing dispersal, had a higher relative contribution to bacterial community assembly processes in the bulk and rhizosphere soils with MP than in those with NT and RT (Fig. 7c). This could be explained by the strong soil disturbance in the soils with MP, which could have led to high 
dispersal rates and thus tended to be more similar to the soil bacterial communities (Stegen et al., 2015; Zaneveld et al., 2017).

The results of the Mantel test also showed that soil $\mathrm{pH}$ was markedly correlated with bacterial community assembly processes (Fig. S1), which was consistent with previous reports (Tripathi et al., 2018). The closer to neutral pH of both the bulk and rhizosphere soils with MP may have reduced the selection pressure from environmental filters (Tripathi et al., 2018) since a neutral pH environment is more suitable for the growth of most bacteria (Madigan, 2012). Moreover, niche-based processes are influenced by not only abiotic factors (environmental filtering) but also biotic interactions (e.g., competition, predation and mutualism) (Zhou and Ning, 2017). Therefore, the soil nutrients and soil pH in NT were not significantly higher than those in the soils with RT, but NT increased the relative importance of stochastic processes because more microbial interactions in soils with NT could lead to alleviation of environmental selection pressure (Bouizgarne et al., 2014; Jiao et al., 2020).

\section{Conclusions}

Our study showed that the compositions, structures and assemblies of bacterial communities in the bulk and rhizosphere soils were significantly affected by tillage practices. Specifically, the relative abundance of nitrogen-fixing bacteria increased, while the bacteria associated with carbon degradation decreased in the soils with NT and RT compared with those with MP. Additionally, the bacterial networks in soils with NT and RT were more robust to environmental disturbances than those in soils with MP. The deterministic processes played a predominant role in the assemblage of bacterial communities under the three tillage practices, and the relative contribution of the homogenizing dispersal process was greater in both the bulk and rhizosphere soils with MP than in those with NT and RT. Soil pH played a major role in mediating bacterial community structures and assembly processes under the different tillage practices. Overall, this study provides a variety of evidence that in comparison to conventional tillage practices, conservation tillage practices were more conducive to biological nitrogen fixation and soil carbon sequestration.

\section{Declarations}

\section{Conflict of interest}

The authors declare that they have no conflicts of interest.

\section{Acknowledgements}

This study was supported from the Key Research Program of Frontier Sciences, Chinese Academy of Sciences (ZDBS-LY-DQC017, QYZDB-SSW-DQC035), the Natural Science Foundation of Heilongjiang Province (D2018009), the Grass-field Rotation Scientist Studio of Heilongjiang Province (202004), 
outstanding youth fund of Heilongjiang Academy of Agricultural Sciences (2020JCQN003), and the Youth Innovation Promotion Association, Chinese Academy of Sciences (2017276).

\section{References}

1. Agler MT, Ruhe J, Kroll S, Morhenn C, Kim S, Weigel D, Kemen EM (2016) Microbial hub taxa link host and abiotic factors to plant microbiome variation. Plos Biol 14:e1002352

2. Allison SD, Wallenstein MD, Bradford MA (2010) Soil-carbon response to warming dependent on microbial physiology. Nat Geosci 3:336-340

3. Alvear M, Rosas A, Rouanet JL, Borie F (2005) Effects of three soil tillage systems on some biological activities in an Ultisol from Southern Chile. Soil Till Res 82:195-202

4. Aronesty E (2011) ea-utils: "Command-line tools for processing biological sequencing data". Durham, NC. http://code.google.com/p/ea-utils

5. Banerjee S, Schlaeppi K, van der Heijden MGA (2018) Keystone taxa as drivers of microbiome structure and functioning. Nat Rev Microbiol 16:567-576

6. Banerjee S, Walder F, Buchi L, Meyer M, Held AY, Gattinger A, Keller T, Charles R, van der Heijden MGA (2019) Agricultural intensification reduces microbial network complexity and the abundance of keystone taxa in roots. ISME J 13:1722-1736

7. Barberan A, Bates ST, Casamayor EO, Fierer N (2012) Using network analysis to explore cooccurrence patterns in soil microbial communities. ISME J 6:343-351

8. Berendsen RL, Pieterse CM, Bakker PA (2012) The rhizosphere microbiome and plant health. Trends Plant Sci 17:478-486

9. Bouizgarne B, Oufdou K, Ouhdouch Y (2014) Actinorhizal and Rhizobial-Legume symbioses for alleviation. In: Plant Microbes Symbiosis: Applied Facets. Springer, New Delhi

10. Busari MA, Kukal SS, Kaur A, Bhatt R, Dulazi AA (2015) Conservation tillage impacts on soil, crop and the environment. Int Soil Water Conse 3:119-129

11. Caporaso JG, Kuczynski J, Stombaugh J, Bittinger K, Bushman FD, Costello EK, Fierer N, Pena AG, Goodrich JK, Gordon JI, Huttley GA, Kelley ST, Knights D, Koenig JE, Ley RE, Lozupone CA, McDonald D, Muegge BD, Pirrung M, Reeder J, Sevinsky JR, Tumbaugh PJ, Walters WA, Widmann J, Yatsunenko T, Zaneveld J, Knight R (2010) QIIME allows analysis of high-throughput community sequencing data. Nat Methods 7:335-336

12. Castrillo G, Teixeira PJPL, Paredes SH, Law TF, de Lorenzo L, Feltcher ME, Finkel OM, Breakfield NW, Mieczkowski P, Jones CD, Paz-Ares J, Dangl JL (2017) Root microbiota drive direct integration of phosphate stress and immunity. Nature 543:513-518

13. Chen RR, Zhong LH, Jing ZW, Guo ZY, Li ZP, Lin XG, Feng YZ (2017) Fertilization decreases compositional variation of paddy bacterial community across geographical gradient. Soil Biol Biochem 114:181-188 
14. Cheng X, Yun Y, Wang H, Ma L, Tian W, Man B, Liu C (2021) Contrasting bacterial communities and their assembly processes in karst soils under different land use. Sci Total Environ 751:142263

15. Cole JR, Chai B, Farris RJ, Wang Q, Kulam SA, McGarrell DM, Garrity GM, Tiedje JM (2005) The Ribosomal Database Project (RDP-II): sequences and tools for high-throughput rRNA analysis. Nucleic Acids Res 33:D294-D296

16. Costello EK, Stagaman K, Dethlefsen L, Bohannan BJ, Relman DA (2012) The application of ecological theory toward an understanding of the human microbiome. Science 336:1255-1262

17. Dang YP, Seymour NP, Walker SR, Bell MJ, Freebairn DM (2015) Strategic tillage in no-till farming systems in Australia's northern grains-growing regions: I. Drivers and implementation. Soil Till Res 152:104-114

18. de Vries M, Scholer A, Ertl J, Xu ZF, Schloter M (2015) Metagenomic analyses reveal no differences in genes involved in cellulose degradation under different tillage treatments. FEMS Microbiol Ecol 91:fiv069

19. Degrune F, Dufrene M, Colinet G, Massart S, Taminiau B, Bodson B, Hiel MP, Daube G, Nezer C, Vandenbol M (2015) A novel sub-phylum method discriminates better the impact of crop management on soil microbial community. Agron Sustain Dev 35:1157-1166

20. Deng Y, Jiang YH, Yang YF, He ZL, Luo F, Zhou JZ (2012) Molecular ecological network analyses. BMC Bioinformatics 13:113

21. Edgar RC (2010) Search and clustering orders of magnitude faster than BLAST. Bioinformatics 26:2460-2461

22. Edgar RC, Haas BJ, Clemente JC, Quince C, Knight R (2011) UCHIME improves sensitivity and speed of chimera detection. Bioinformatics 27:2194-2200

23. Falkowski PG, Fenchel T, Delong EF (2008) The microbial engines that drive Earth's biogeochemical cycles. Science 320:1034-1039

24. Fan KK, Cardona C, Li YT, Shi Y, Xiang XJ, Shen CC, Wang HF, Gilbert JA, Chu HY (2017) Rhizosphereassociated bacterial network structure and spatial distribution differ significantly from bulk soil in wheat crop fields. Soil Biol Biochem 113:275-284

25. Fan KK, Delgado-Baquerizo M, Guo XS, Wang DZ, Wu YY, Zhu M, Yu W, Yao HY, Zhu YG, Chu HY (2019) Suppressed $\mathrm{N}$ fixation and diazotrophs after four decades of fertilization. Microbiome 7:143

26. Feng Y, Chen R, Stegen JC, Guo Z, Zhang J, Li Z, Lin X (2018) Two key features influencing community assembly processes at regional scale: initial state and degree of change in environmental conditions. Mol Ecol 27:5238-5251

27. Fierer $N$ (2017) Embracing the unknown: disentangling the complexities of the soil microbiome. Nat Rev Microbiol 15:579-590

28. Goberna M, Garcia C, Verdu M (2014) A role for biotic filtering in driving phylogenetic clustering in soil bacterial communities. Glob Ecol Biogeogr 23:1346-1355 
29. Guo LJ, Zheng SX, Cao CG, Li CF (2016) Tillage practices and straw-returning methods affect topsoil bacterial community and organic $\mathrm{C}$ under a rice-wheat cropping system in central China. Sci Rep 6:33155

30. Herren CM, McMahon KD (2018) Keystone taxa predict compositional change in microbial communities. Environ Microbiol 20:2207-2217

31. Hobbs PR, Sayre K, Gupta R (2008) The role of conservation agriculture in sustainable agriculture. Philos Trans R Soc B-Biol Sci 363:543-555

32. Hoflich G, Tauschke M, Kuhn G, Werner K, Frielinghaus M, Hohn W (1999) Influence of long-term conservation tillage on soil and rhizosphere microorganisms. Biol Fertil Soils 29:81-86

33. Jiang Y, Li S, Li R, Zhang J, Liu Y, Lv L, Zhu H, Wu W, Li W (2017) Plant cultivars imprint the rhizosphere bacterial community composition and association networks. Soil Biol Biochem 109:145-155

34. Jiao S, Lu Y (2020) Soil pH and temperature regulate assembly processes of abundant and rare bacterial communities in agricultural ecosystems. Environ Microbiol 22:1052-1065

35. Jiao S, Yang Y, Xu Y, Zhang J, Lu Y (2020) Balance between community assembly processes mediates species coexistence in agricultural soil microbiomes across eastern China. ISME J 14:202216

36. Johnson AM, Hoyt GD (1999) Changes to the soil environment under conservation tillage. HortTechnology 9:380-393

37. Kalita M, Malek W (2020) Root nodules of Genista germanica harbor Bradyrhizobium and Rhizobium bacteria exchanging nodC and nodZ genes. Syst Appl Microbiol 43:126026

38. Kalyuzhnaya MG, Beck DAC, Vorobev A, Smalley N, Kunkel DD, Lidstrom ME, Chistoserdova L (2012) Novel methylotrophic isolates from lake sediment, description of Methylotenera versatilis sp. nov. and emended description of the genus Methylotenera. Int J Syst Evol Micr 62:106-111

39. Kitano H (2004) Biological robustness. Nat Rev Genet 5:826-837

40. Krause AE, Frank KA, Mason DM, Ulanowicz RE, Taylor WW (2003) Compartments revealed in foodweb structure. Nature 426:282-285

41. Lauber CL, Hamady M, Knight R, Fierer N (2009) Pyrosequencing-based assessment of soil pH as a predictor of soil bacterial community structure at the continental scale. Appl Environ Microb 75:5111-5120

42. Lin Y, Ye G, Luo J, Di HJ, Liu D, Fan J, Ding W (2018) Nitrosospira cluster 8a plays a predominant role in the nitrification process of a subtropical Ultisol under long-term inorganic and organic fertilization. Appl Environ Microbiol 84:e01031

43. Liu XB, Jin J, Wang GH, Herbert SJ (2008) Soybean yield physiology and development of highyielding practices in Northeast China. Field Crop Res 105:157-171

44. Liu ZX, Liu JJ, Yu ZH, Yao Q, Li YS, Liang AZ, Zhang W, Mi G, Jin J, Liu XB, Wang GH (2020) Longterm continuous cropping of soybean is comparable to crop rotation in mediating microbial 
abundance, diversity and community composition. Soil Till Res 197:104503

45. Louca S, Parfrey LW, Doebeli M (2016) Decoupling function and taxonomy in the global ocean microbiome. Science 353:1272-1277

46. Lu RK (1999) Soil argrochemistry analysis protocoes. China Agriculture Science Press, Beijing

47. Ma B, Wang Y, Ye S, Liu S, Stirling E, Gilbert JA, Faust K, Knight R, Jansson JK, Cardona C, Rottjers L, Xu J (2020) Earth microbial co-occurrence network reveals interconnection pattern across microbiomes. Microbiome 8:82

48. Macchi M, Martinez M, Neme Tauil RM, Valacco MP, Morelli IS, Coppotell BM (2018) Insights into the genome and proteome of Sphingomonas paucimobilis strain 20006FA involved in the regulation of polycyclic aromatic hydrocarbon degradation. World J Microb Biot 34:7

49. Madigan M (2012) Brock Biology of Microorganisms. In: thirteenth ed. (Upper Saddle River, New Jersey), pp. 271-282

50. Mannisto MK, Kurhela E, Tiirola M, Haggblom MM (2013) Acidobacteria dominate the active bacterial communities of Arctic tundra with widely divergent winter-time snow accumulation and soil temperatures. FEMS Microbiol Ecol 84:47-59

51. Montgomery DR (2007) Soil erosion and agricultural sustainability. Proc Natl Acad Sci USA 104:13268-13272

52. Moreau D, Bardgett RD, Finlay RD, Jones DL, Philippot L (2019) A plant perspective on nitrogen cycling in the rhizosphere. Funct Ecol 33:540-552

53. Naqqash T, Imran A, Hameed S, Shahid M, Majeed A, Iqbal J, Hanif MK, Ejaz S, Malik KA (2020) First report of diazotrophic brevundimonas spp. as growth enhancer and root colonizer of potato. Sci Rep 10:12893

54. Noda S, Miyazaki T, Tanaka T, Ogino C, Kondo A (2012) Production of streptoverticillium cinnamoneum transglutaminase and cinnamic acid by recombinant streptomyces lividans cultured on biomass-derived carbon sources. Bioresource Technol 104:648-651

55. Ofiteru ID, Lunn M, Curtis TP, Wells GF, Criddle CS, Francis CA, Sloan WT (2010) Combined niche and neutral effects in a microbial wastewater treatment community. Proc Natl Acad Sci USA 107:1534515350

56. Olesen JM, Bascompte J, Dupont YL, Jordano P (2007) The modularity of pollination networks. Proc Natl Acad Sci USA 104:19891-19896

57. Philippot L, Raaijmakers JM, Lemanceau P, van der Putten WH (2013) Going back to the roots: the microbial ecology of the rhizosphere. Nat Rev Microbiol 11:789-799

58. Puerta VL, Six J, Wittwer R, van der Heijden M, Pereira EIP (2019) Comparable bacterial-mediated nitrogen supply and losses under organic reduced tillage and conventional intensive tillage. Eur $\mathrm{J}$ Soil Biol 95:103121

59. R Development Core Team (2016) R: a language and environment for statistical computing. R Foundation for Statistical Computing, Vienna, Austria URL. https://www.R-project.org/ 
60. Ren L, Fan SH, Wang JH, Ruth N, Qiao C, Jia Y, Yan YC (2017) Complete genome sequence of a phthalic acid esters degrading Mycobacterium sp. YC-RL4). Braz J Microbiol 48:607-609

61. Rivas R, Martens M, De Lajudie P, Willems A (2009) Multilocus sequence analysis of the genus Bradyrhizobium. Syst Appl Microbiol 32:101-110

62. Roper WR, Duckworth OW, Grossman JM, Israel DW (2020) Rhizobium leguminosarum strain combination effects on nodulation and biological nitrogen fixation with Vicia villosa. Appl Soil Ecol 156:103703

63. Sainju UM, Lenssen AW, Caesar-TonThat T, Jabro JD, Lartey RT, Evans RG, Allen BL (2011) Dryland residue and soil organic matter as influenced by tillage, crop rotation, and cultural practice. Plant Soil 338:27-41

64. Sanjenbam P, Buddidathi R, Venkatesan R, Shivaprasad PV, Agashe D (2020) Phenotypic diversity of Methylobacterium associated with rice landraces in North-East India. PLoS ONE 15:e0228550

65. Shi Y, Delgado-Baquerizo M, Li Y, Yang Y, Zhu YG, Penuelas J, Chu H (2020) Abundance of kinless hubs within soil microbial networks are associated with high functional potential in agricultural ecosystems. Environ Int 142:105869

66. Shi Y, Li YT, Xiang XJ, Sun RB, Yang T, He D, Zhang KP, Ni YY, Zhu YG, Adams JM, Chu HY (2018) Spatial scale affects the relative role of stochasticity versus determinism in soil bacterial communities in wheat fields across the North China Plain. Microbiome 6:27

67. Six J, Paustian K, Elliott ET, Combrink C (2000) Soil structure and organic matter: I. Distribution of aggregate-size classes and aggregate-associated carbon. Soil Sci Soc Am J 64:681-689

68. Soe KM, Htwe AZ, Moe K, Tomomi A, Yamakawa T (2020) Diversity and effectivity of indigenous Mesorhizobium strains for Chickpea (Cicer arietinum L.) in Myanmar. Agronomy-Basel 10:287

69. Stegen JC, Lin X, Fredrickson JK, Chen XY, Kennedy DW, Murray CJ, Rockhold MK, Konopka A (2013) Quantifying community assembly processes and identifying features that impose them. ISME $J$ 7:2069-2079

70. Stegen JC, Lin X, Fredrickson JK, Konopka AE (2015) Estimating and mapping ecological processes influencing microbial community assembly. Front Microbiol 6:370

71. Stegen JC, Lin X, Konopka AE, Fredrickson JK (2012) Stochastic and deterministic assembly processes in subsurface microbial communities. ISME J 6:1653-1664

72. Steinkellner S, Langer I (2004) Impact of tillage on the incidence of Fusarium spp. in soil. Plant Soil 267:13-22

73. Sun M, Ren AX, Gao ZQ, Wang PR, Mo F, Xue LZ, Lei MM (2018a) Long-term evaluation of tillage methods in fallow season for soil water storage, wheat yield and water use efficiency in semiarid southeast of the Loess Plateau. Field Crop Res 218:24-32

74. Sun R, Li W, Dong W, Tian Y, Hu C, Liu B (2018b) Tillage changes vertical distribution of soil bacterial and fungal communities. Front Microbiol 9:699 
75. Thebault E, Fontaine $C$ (2010) Stability of ecological communities and the architecture of mutualistic and trophic networks. Science 329:853-856

76. Tong X, Wang X, He X, Wang Z, Li W (2020) Effects of antibiotics on microbial community structure and microbial functions in constructed wetlands treated with artificial root exudates. Environ SciProc Imp 22:217

77. Tripathi BM, Stegen JC, Kim M, Dong K, Adams JM, Lee YK (2018) Soil pH mediates the balance between stochastic and deterministic assembly of bacteria. ISME J 12:1072-1083

78. Turner TR, Ramakrishnan K, Walshaw J, Heavens D, Alston M, Swarbreck D, Osbourn A, Grant A, Poole PS (2013) Comparative metatranscriptomics reveals kingdom level changes in the rhizosphere microbiome of plants. ISME J 7:2248-2258

79. Tyler HL (2019) Bacterial community composition under long-term reduced tillage and no till management. J Appl Microbiol 126:1797-1807

80. Wang F, Zhou JZ, Sun B (2014) Structure of functional ecological networks of soil microbial communities for nitrogen transformations and their response to cropping in major soils in eastern China. Chin Sci Bull (Chin Ver) 59:387-396

81. Wang H, Li X, Li X, Wang J, Li X, Guo Q, Yu Z, Yang T, Zhang H (2020a) Long-term no-tillage and different residue amounts alter soil microbial community composition and increase the risk of maize root rot in northeast China. Soil Till Res 196:104452

82. Wang Y, Liu L, Yang J, Duan Y, Luo Y, Taherzadeh MJ, Li Y, Li H, Awasthi MK, Zhao Z (2020c) The diversity of microbial community and function varied in response to different agricultural residues composting. Sci Total Environ 715:136983

83. Wang ZT, Li T, Li YZ, Zhao DQ, Han J, Liu Y, Liao YC (2020b) Relationship between the microbial community and catabolic diversity in response to conservation tillage. Soil Till Res 196:104431

84. Webb C, Ackerly D, Mcpeek M, Donoghue M (2002) Phylogenies and community ecology. Annu Rev Ecol Syst 33:475-505

85. Xia X, Zhang P, He L, Gao X, Li W, Zhou Y, Li Z, Li H, Yang L (2019) Effects of tillage managements and maize straw returning on soil microbiome using $16 \mathrm{~S}$ rDNA sequencing. $J$ Integr Plant Biol 61:765-777

86. Xue YF, Tian J, Quine TA, Powlson D, Xing KX, Yang LY, Kuzyakov Y, Dungait JAJ (2020) The persistence of bacterial diversity and ecosystem multifunctionality along a disturbance intensity gradient in karst soil. Sci Total Environ 748:142381

87. Yan Y, Kuramae EE, de Hollander M, Klinkhamer PGL, van Veen JA (2017) Functional traits dominate the diversity-related selection of bacterial communities in the rhizosphere. ISME J 11:56-66

88. Ye GP, Banerjee S, He JZ, Fan JB, Wang ZH, Wei XY, Hu HW, Zheng Y, Duan CJ, Wan S, Chen JM, Lin YX (2021) Manure application increases microbiome complexity in soil aggregate fractions: Results of an 18-year field experiment. Agr Ecosyst Environ 307:107249

89. Zaneveld JR, McMinds R, Thurber RV (2017) Stress and stability: applying the Anna Karenina principle to animal microbiomes. Nat Microbiol 2:17121 
90. Zhang B, He H, Ding X, Zhang X, Zhang X, Yang X, Filley TR (2012) Soil microbial community dynamics over a maize (Zea mays) growing season under conventional- and no-tillage practices in a rainfed agroecosystem. Soil Till Res 124:153-160

91. Zhao X, Liu SL, Pu C, Zhang XQ, Xue JF, Ren YX, Zhao XL, Chen F, Lal R, Zhang HL (2017) Crop yields under no-till farming in china: a meta-analysis. Eur J Agron 84:67-75

92. Zhou JZ, Deng Y, Zhang P, Xue K, Liang YT, Van Nostrand JD, Yang YF, He ZL, Wu LY, Stahl DA, Hazen TC, Tiedje JM, Arkin AP (2014) Stochasticity, succession, and environmental perturbations in a fluidic ecosystem. Proc Natl Acad Sci USA 111:836-845

93. Zhou JZ, Ning DL (2017) Stochastic community assembly: Does it matter in microbial ecology? Microbiol Mol Biol Rev 81:e00002-e17

94. Zuber SM, Villamil MB (2016) Meta-analysis approach to assess effect of tillage on microbial biomass and enzyme activities. Soil Boil Biochem 97:176-187

\section{Figures}

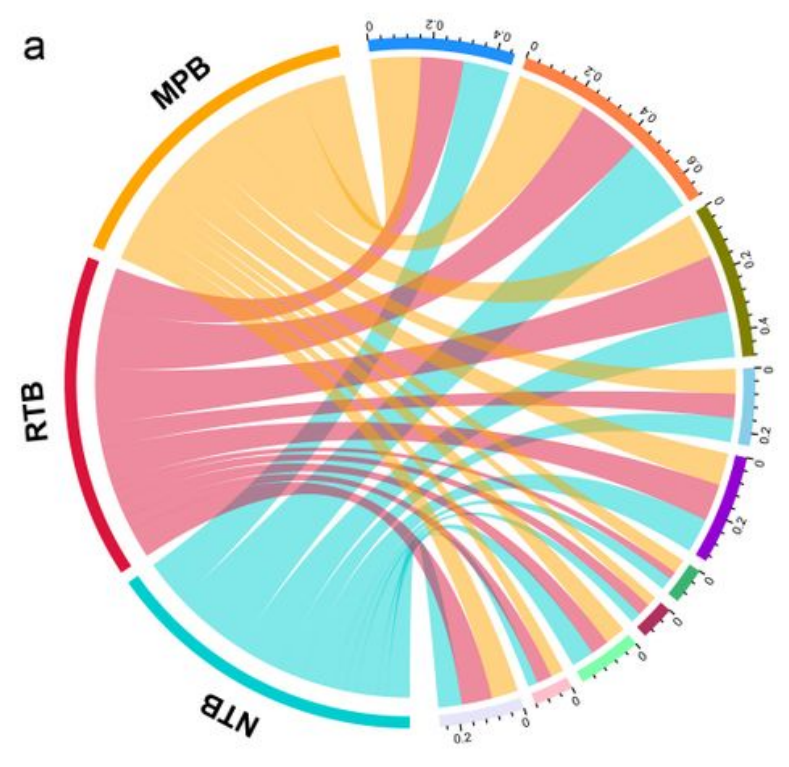

Bulk soil

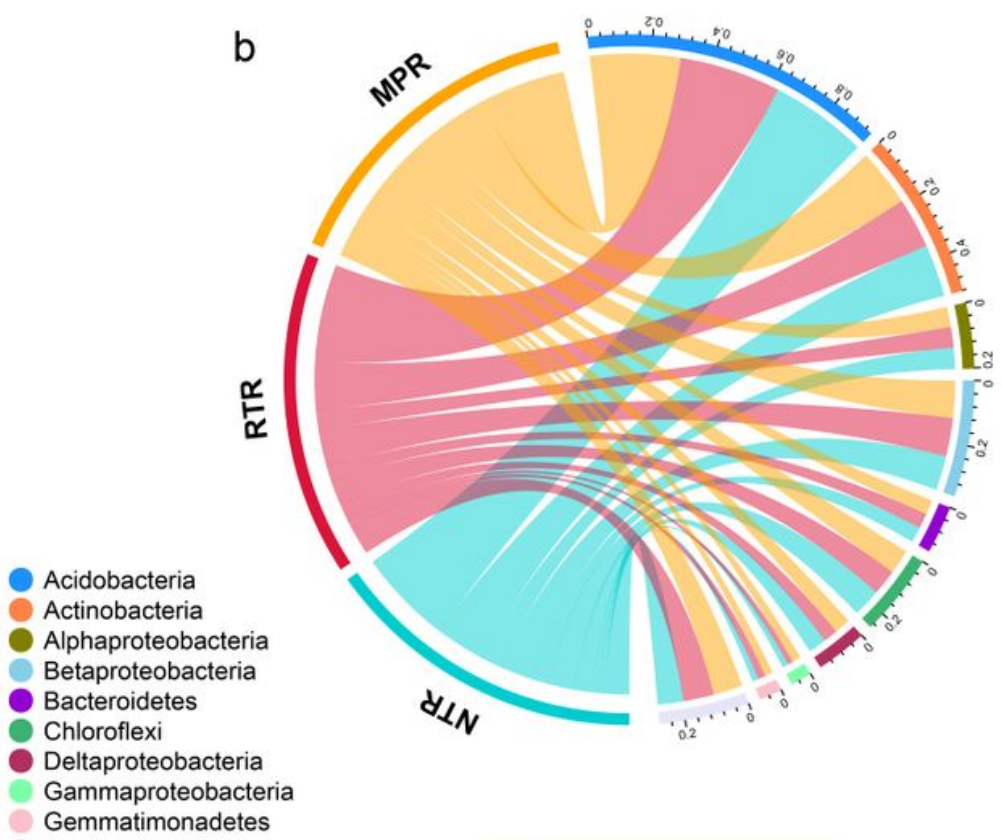

Rhizosphere soil

\section{Figure 1}

The bacterial taxonomic distribution is shown as a circos plot at the phylum/class level in the bulk (a) and rhizosphere (b) soils under the different tillage practices. The thickness of each ribbon represents the relative abundances of bacterial phyla/classes. NT, RT and MP represent no-tillage, ridge tillage and moldboard plow tillage, respectively; B: bulk soil; R: rhizosphere soil. For example, NTB represents soil samples collected under no-tillage in bulk soils. 
a
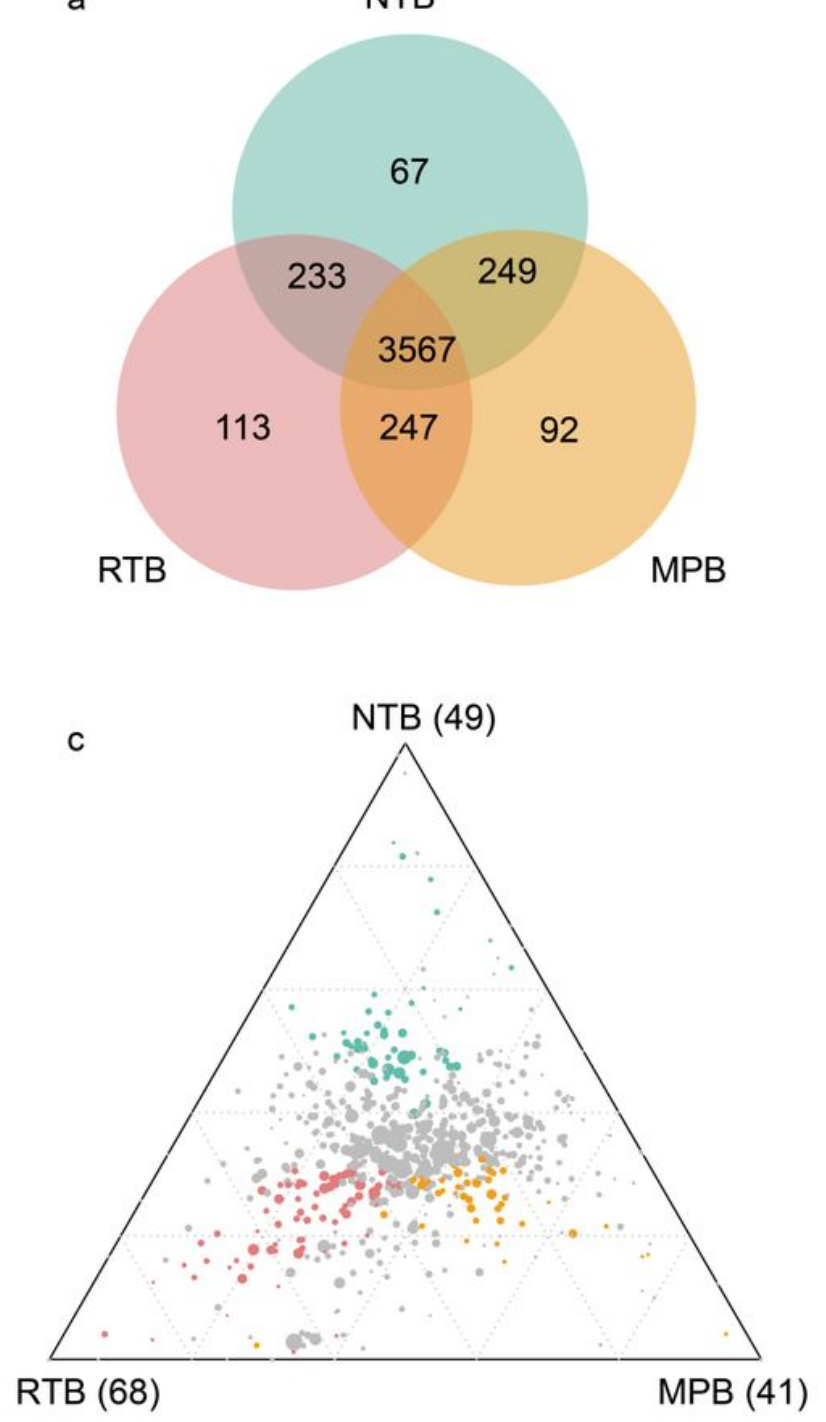

b
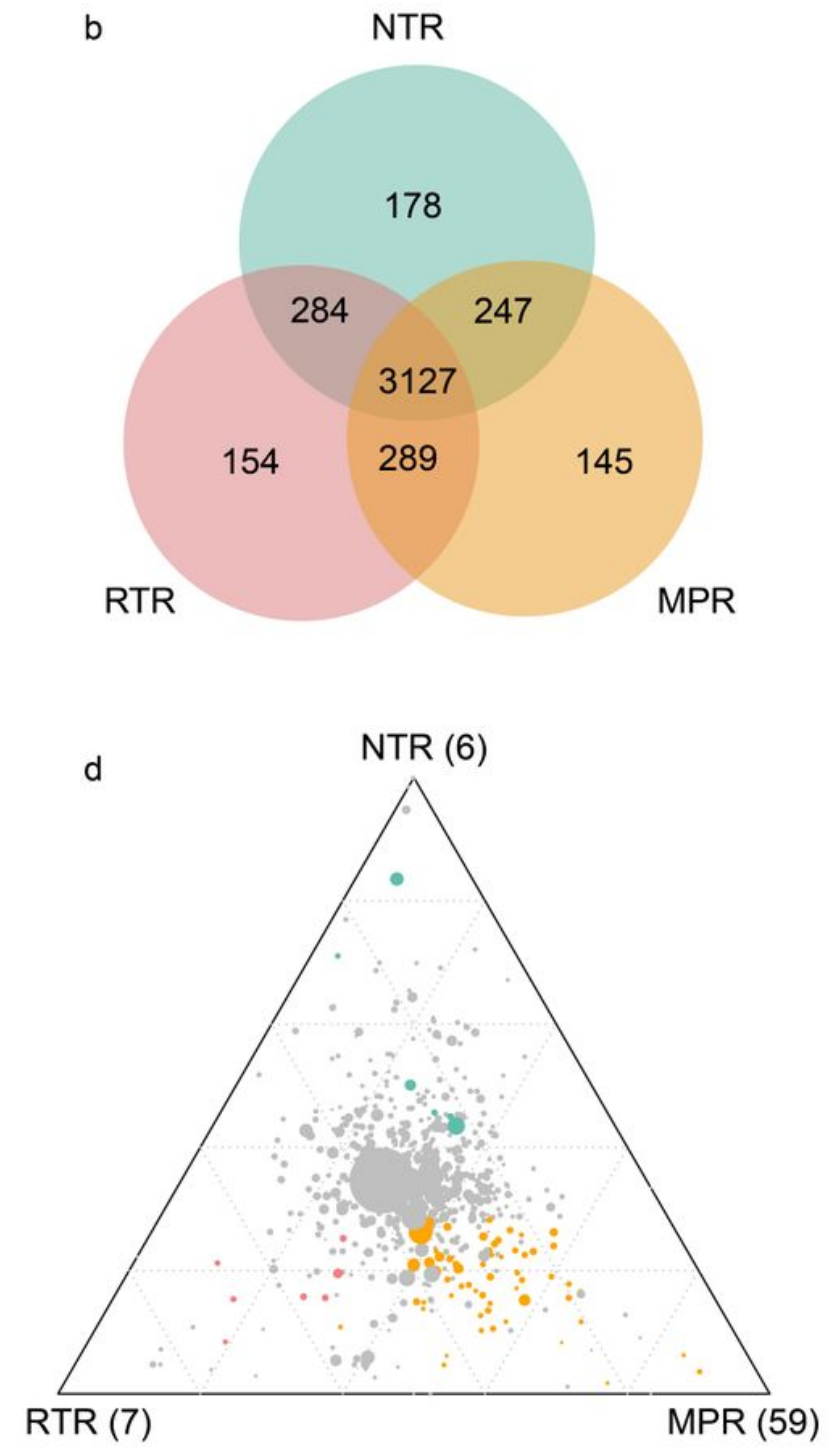

\section{Figure 2}

Venn diagrams showing the number of shared and unique bacterial OTUs in the bulk (a) and rhizosphere (b) soils under the different tillage practices. Ternary plot showing the enriched bacterial OTUs in the bulk (c) and rhizosphere (d) soils. Each circle represents one OTU, and the sizes of each circle represent its relative abundance. The treatment description is same as Figure 1. Green, red and orange circles mark OTUs significantly enriched in soils with NT, RT and MP, respectively. The values in the brackets indicate the number of enriched OTUs. 

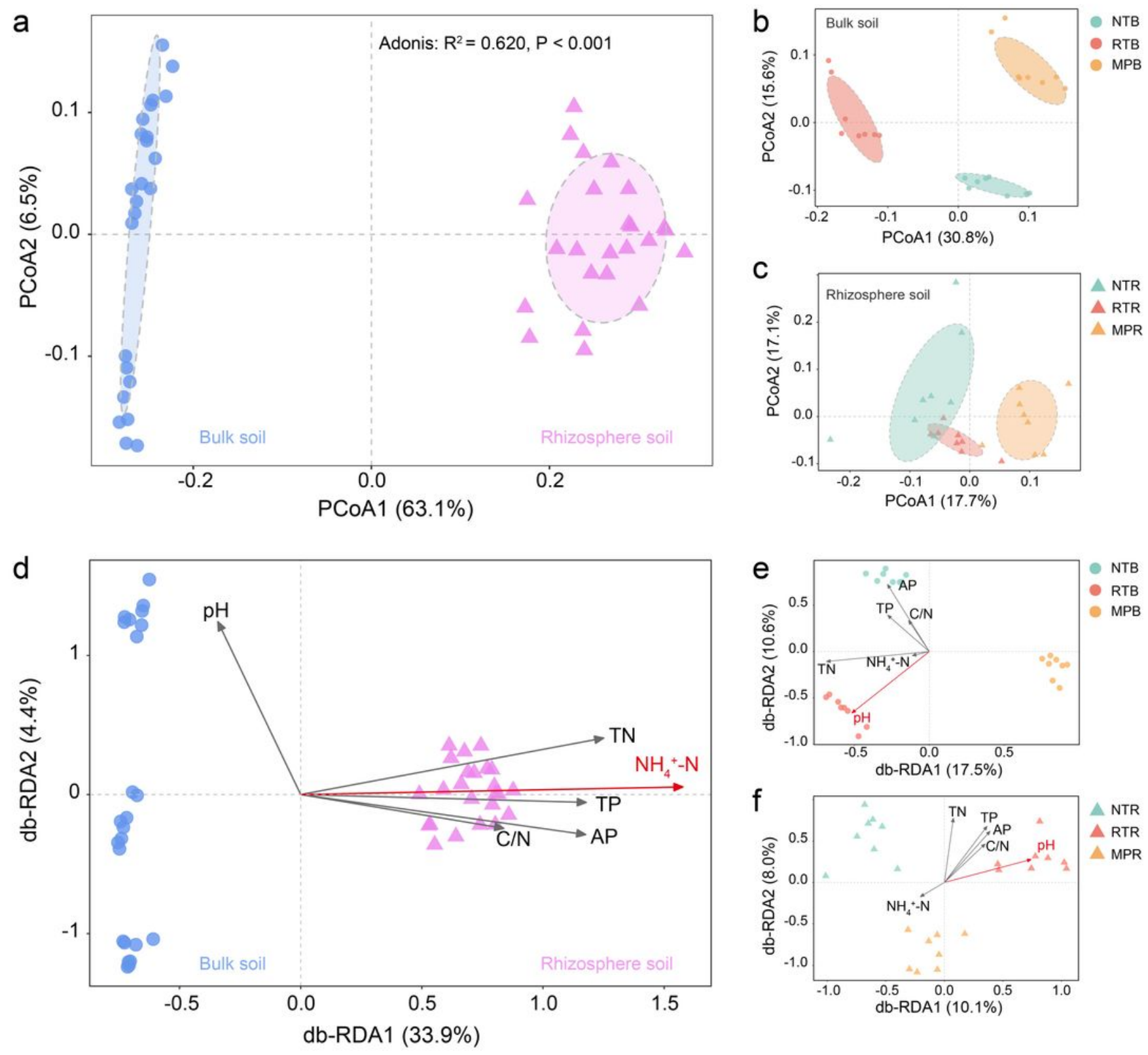

\section{Figure 3}

Principal coordination analysis (PCOA) of soil bacterial community structures and distance-based redundancy analysis (db-RDA) of the relationships between soil environmental factors and soil bacterial communities in the bulk and rhizosphere soils among the three tillage practices based on Bray-Curtis distance. All 48 soil samples ( $a$ and $d$ ) and 24 bulk soil ( $b$ and e) and rhizosphere soil samples ( $c$ and $f$ ). NT, RT and MP represent no-tillage, ridge tillage and moldboard plow tillage, respectively; B: bulk soil; R: rhizosphere soil. 

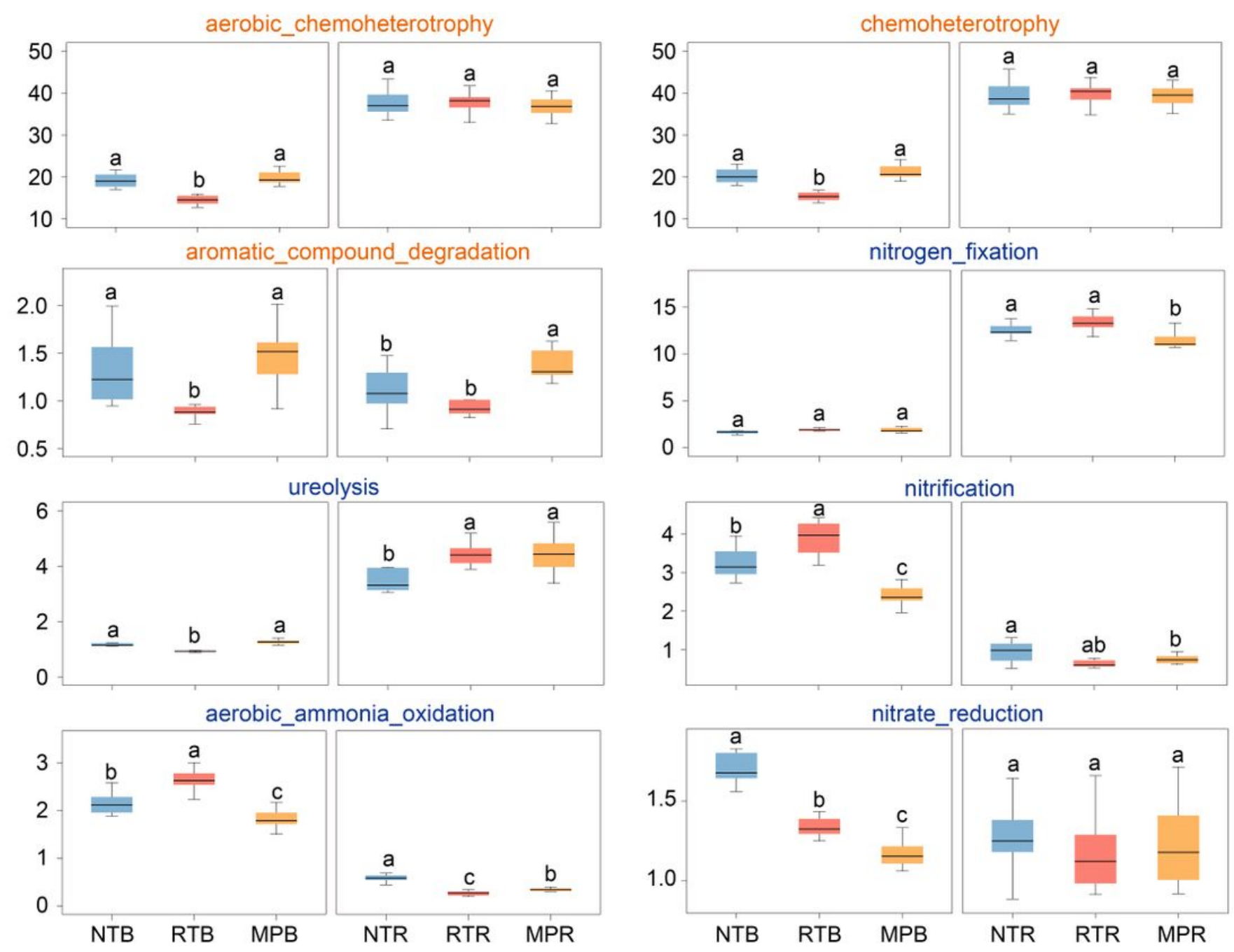

\section{Figure 4}

Functional prediction of bacterial communities in the bulk and rhizosphere soils under the different tillage practices using FAPROTAX. Different letters indicate significant differences among the three tillage treatments at the $P<0.05$ level. The dominant functional groups (mean relative abundance $>1 \%$ in at least one treatment) associated with the soil carbon cycle and nitrogen cycle are highlighted in orange and blue font, respectively. NT, RT and MP represent no-tillage, ridge tillage and moldboard plow tillage, respectively; B: bulk soil; R: rhizosphere soil. 


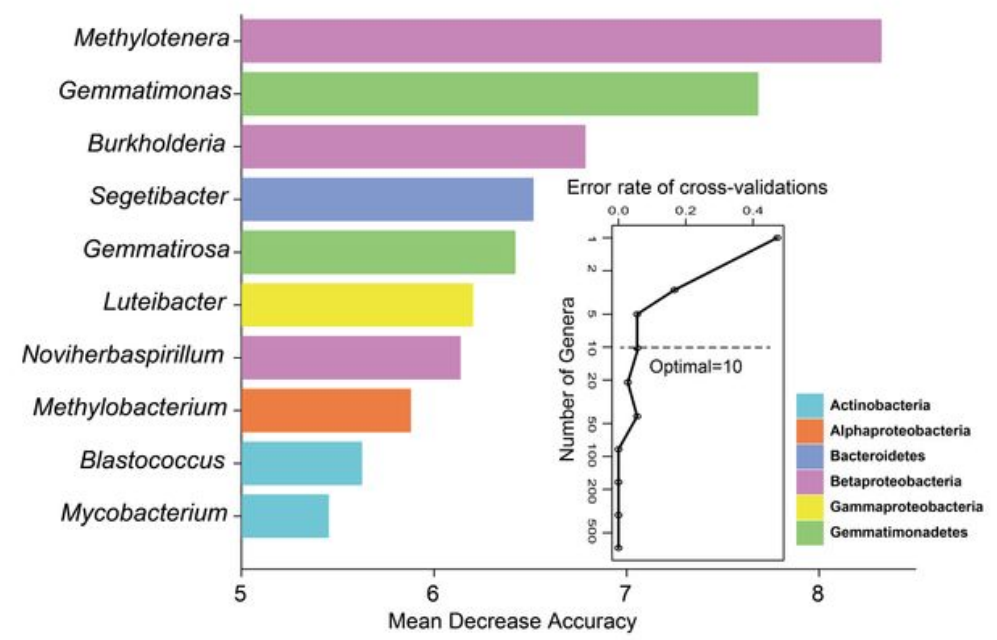

b

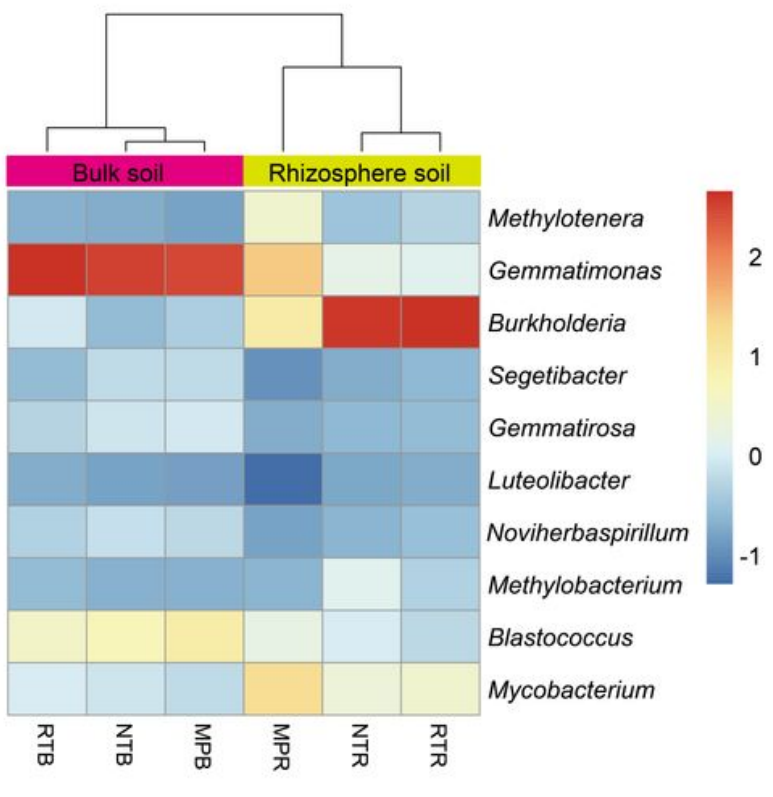

\section{Figure 5}

The bacterial biomarkers were identified at the genus level by random forest analysis. The top 10 biomarkers were ranked in descending order of importance (a). Heatmap showing the variations in the relative abundances of the biomarkers in the bulk and rhizosphere soils under the different tillage practices (b). NT, RT and MP represent no-tillage, ridge tillage and moldboard plow tillage, respectively; B: bulk soil; R: rhizosphere soil. 


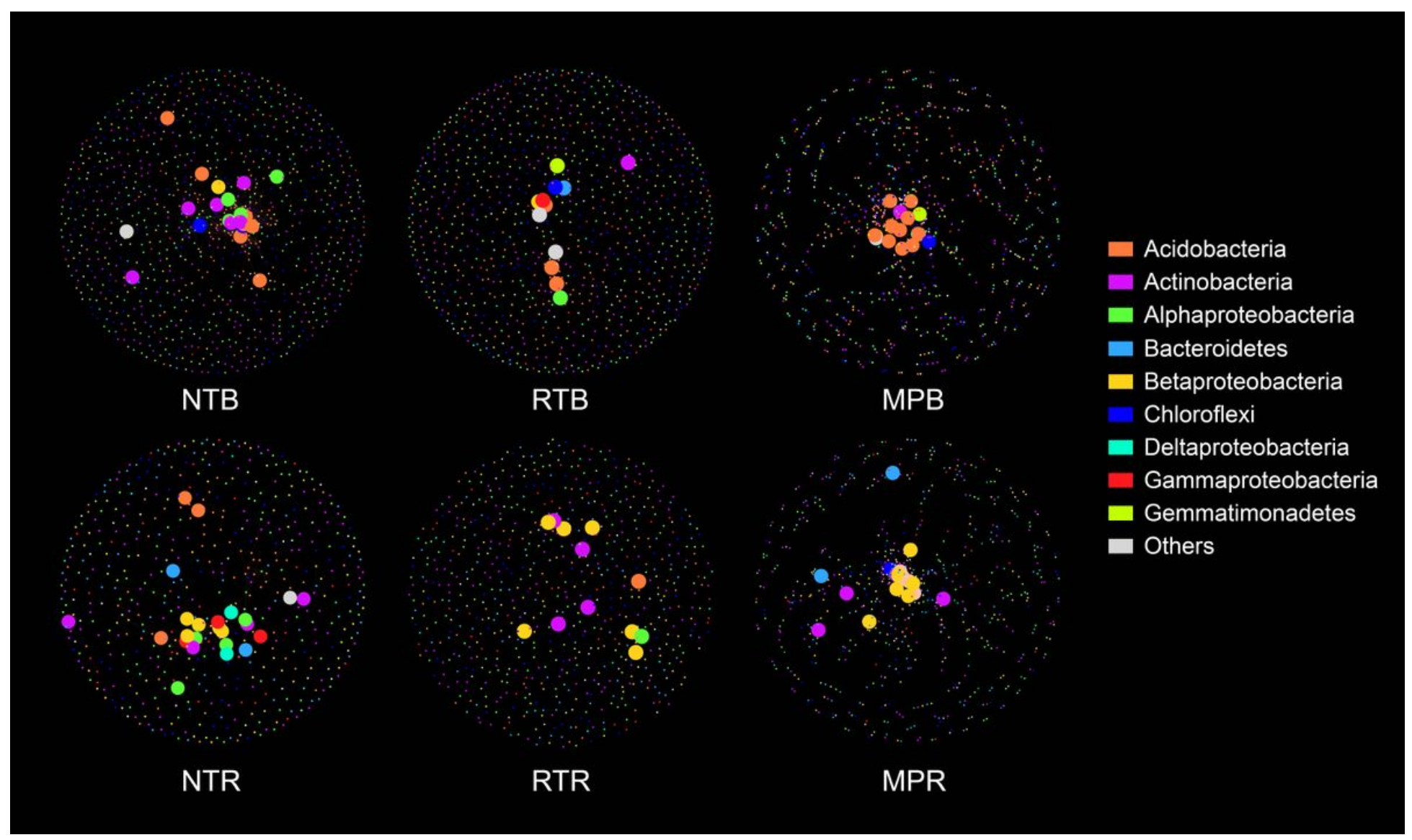

\section{Figure 6}

Bacterial ecological networks displayed at the OTU level in the bulk and rhizosphere soils under the different tillage practices. A connection indicates a strong (Spearman's $\rho>0.6)$ and significant $(P<0.01)$ correlation. Each node represents a unique OTU. The nodes colored by phyla/classes and the keystone taxa are magnified. NT, RT and MP represent no-tillage, ridge tillage and moldboard plow tillage, respectively; B: bulk soil; R: rhizosphere soil. 


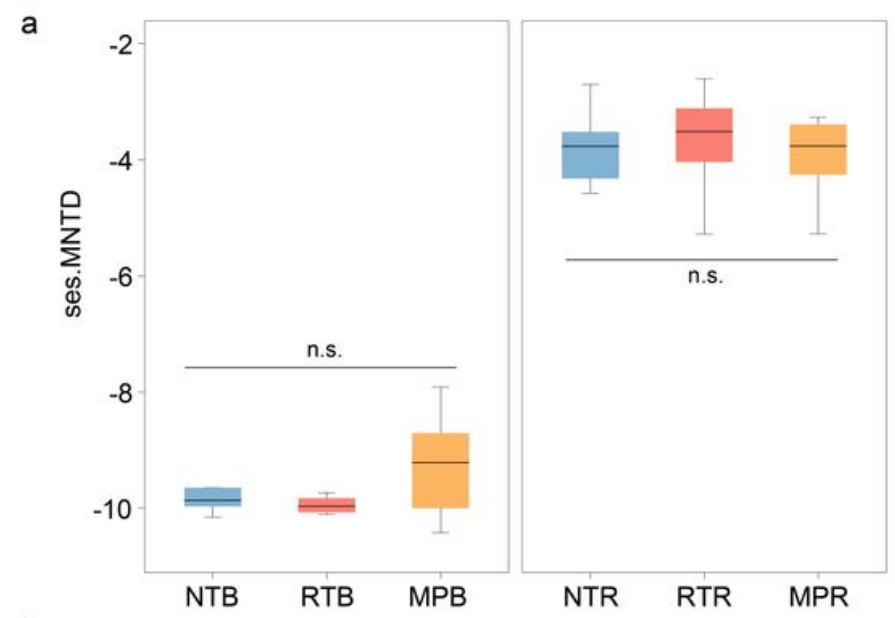

b

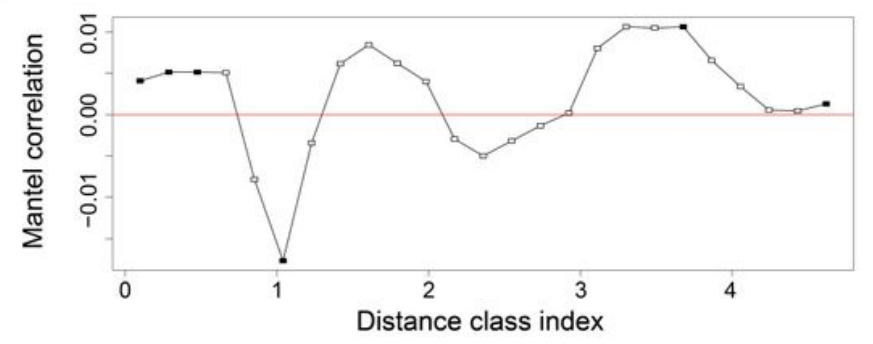

C


Figure 7

Relative impacts of ecological processes on bacterial community assembly under the different tillage practices in the bulk and rhizosphere soils. The standardized effect size measure of the mean nearest taxon distance (ses.MNTD) was shown in the bulk and rhizosphere soils within the different tillage practices $(a)$, n.s. represent no significant difference $(P>0.05)$. Mantel correlograms between the phylogenetic distances of two OTUs and their niche distances. Solid points indicate significant correlations $(P<0.05)(b)$. The relative contributions of five ecological assembly processes with the three tillage practices (c). NT, RT and MP represent no-tillage, ridge tillage and moldboard plow tillage, respectively; B: bulk soil; R: rhizosphere soil.

\section{Supplementary Files}

This is a list of supplementary files associated with this preprint. Click to download.

- SUPPORTINGINFORMATION.rar 